\title{
Evaluation of Changes in Selected Life Areas from the Perspective of Shelter Users in the Czech Republic
}

\section{K. Glumbikova (Katerina Glumbikova)ำ P. Rusnok (Pavel Rusnok)², R, Polakova

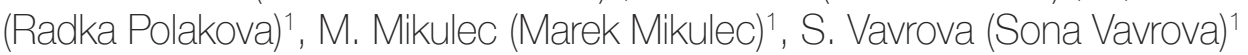

${ }^{1}$ Faculty of Social Studies, University of Ostrava, Moravska Ostrava,

Czech Republic.

${ }^{2}$ Institute for Research and Applications of Fuzzy Modeling, University of Ostrava, Moravska Ostrava, Czech Republic.

\section{E-mail address:}

katerina.glumbikova@osu.cz

\section{Reprint address:}

Katerina Glumbikova

Ceskobratrska 16

70200 Moravska Ostrava

Czech Republic

Source: Clinical Social Work and Health Intervention

Volume: 11

Issue: 4

Pages: $57-63$

Cited references: 31

\section{Reviewers:}

Daria Kimuli

Catholic University of Eastern Africa, Nairobi, Kenya

Gabriela Lezcano

University of California, San Francisco, USA

\section{Keywords:}

Homelessness. Evaluation of Life Situation. Shelter Users Perspective.

\section{Publisher:}

International Society of Applied Preventive Medicine i-gap

CSWHI 2020; 11(4): 57 -63; DOI: 10.22359/cswhi_11_4_08 CC Clinical Social Work and Health Intervention

\section{Abstract:}

OBJECTIVE: The objective of the paper is to evaluate the ongoing changes in specific life areas from the perspective of shelter users.

DESIGN: In order to fulfil this objective, we have chosen a quantitative research strategy.

PARTICIPANTS: The data was collected from 135 participants, people living in shelters for homeless people.

METHODS: We used tailor made questionnaire based on metha-analysis.

RESULTS: The research results show that the changes in individual life areas are interconnected and the users go through 
positive changes in shelters as well as negative changes. An important finding was the perceived relationship between the acquisition and keeping of stable housing and self-development, self-confidence, and self-efficacy. Respondent's sex and length of stay in the shelter house were found to be important factors affecting the changes in life situations.

CONCLUSION: Based on the research results, implications for social work in shelters have been determined.

\section{Introduction}

The paper conceptually stems from two sets of contemporary trends in social work with homeless people. The first is the dynamics of the characteristics of the target group, and the second set is the characteristics of social work (with the given target group) in contemporary social work in the Czech Republic. In relation to the target group of homeless people, there are four tendencies both at the national (Czech Republic) and the international levels:

a) increase in homeless people and people in danger of becoming homeless (Feantsa, 2019; Kucharova \& Janurova, 2016); b) constant or increasing number of homeless people who fail to be integrated into permanent housing due to the permeable system of social housing (Glumbikova, 2017; Towers, 2000); c) increase in the complexity of problems of homeless people (Gardner, 2006); d) persistent oppressive approach to homeless people (Anooshian, 2005; Glumbikova et al., 2018a).

The Czech Republic currently does not have a law on social housing, only a Concept of Preventing and Tackling Homelessness Issues in the Czech Republic until 2020 (MoLSA, 2013) and the Social Housing Concept of Czech Republic 2015-2025 (MoLSA, 2015), which define the basic principles of solving the issue of homelessness. However, these documents do not hold the validity of a law and their principles are not enforceable. The above-mentioned reveals that the help to homeless people in the Czech Republic is currently primarily in the agenda of social services.

Concerning the above-mentioned, it is more important than at any other time to evaluate changes in users' life situations which occur in social work in social services and shelters. The objective of this paper is to evaluate the perceived changes in specific areas of a life situation through shelter user's perspective and based on that, to determine the implications of social work in shelters.

\section{Areas of evaluating the life situation of people living in shelters}

There is currently no standardized tool for assessing the changes in the life situation of homeless people in the Czech Republic, so we made meta-analysis of this topic to find all relevant areas of assessment the changes in the life situation of homeless people. It included expert studies in the Czech, English, and German language (not older than 2000). The meta-analysis also included texts from the following databases: PROQUEST, WISO, SAGE, EBSCO, and SpringerLink. Within the meta-analysis, we looked for the key words: future, hope in homeless people, recovery, factors of changes, individual planning; and their equivalents in the Czech and German languages. The data was processed using thematic analysis. Based on a meta-analysis of expert publications related to this issue, the evaluation of a life situation and desired future of homeless people may include the following topics: acquisition and retention the housing (f. e. Groundswell, 2015; Lux \& Mikeszova, 2013; Patterson \& Tweed, 2009), financial literacy (f. e. Glumbikova, 2017; Shobe \& Page-Adams, 2001, health (f. e. Fitzpatrick-Lewis et al., 2011; Laporte et al., 2010; Luo \& McGrant, 2006; social sources of support (f. e. Glumbikova, 2017; Groundswell, 2015; Mayock et al., 2011; Neale \& Stevenson, 2015; Shier et al., 2010; Webber \& Joubert, 2015; relying on oneself and self-evaluation (f. e. Gerull \& Merckens, 2012; Groundswell, 2015; Lux \& Mikeszova, 2013; Shier et al., 2010; Weber \& Joubert, 2015); meaningful spending of leisure time: work, meaningful spending of leisure time: self-development (f. e. Gerull \& Merckens, 2012; Groundswell, 2015; Lens et al., 2009 worries about the future, and life stability (f. e. Foster \& 
Spencer, 2011; Henwood et al., 2015; Patterson \& Tweed, 2009.

\section{Methodology}

The objective of the research was to evaluate the shift in relevant areas of life in the perspective of shelter male and female users. The selection of the participants was carried out in the form of the intentional sampling with following criteria: a) affiliation to a region (selection from all 14 regions of the Czech Republic); b) the target group of the shelter (men and women); c) voluntary participation in the research. Altogether, 135 persons participated in the research, 95 men and 40 women. The median of the length of stay in the shelter was 6 months. The maximum stated length was 61 months. Within the research, there were 61 persons who stayed in the shelter longer than the stated median (median included) (out of whom 38 men and 23 women) and 57 persons who lived in the shelter shorter than the stated median (out of whom 41 men and 16 women).

The data collection technique was a tailor made questionnaire which was constructed based on the search of expert publications processed by the meta-analysis of the expert publications mentioned above. The questionnaire was piloted with the target group $(\mathrm{N}=8)$ with respect to the intelligibility of the questions by the target group. The questionnaire held the nature of 10 evaluated scales: (acquisition and retention of housing; financial literacy; health; social sources of support; relying on oneself; self-evaluation; meaningful spending of leisure time: work, meaningful spending of leisure time; self-development; worries about the future, and life stability), which the users filled in with numerical data (perceived level of target acquisition in the given area in the range 1-10) at the time of entering the shelter (past) and at the moment (present). The questionnaire was administered using assisted administration, when the shelter user always filled in the questionnaire in cooperation with the researcher.

Within the research, we determined the following research objectives (RO) based on the literature review (Glumbikova et al., 2018a; Lux \& Mikeszova, 2013):

R01: Find out if the scale acquisition and retention of housing is mutually (interconnected) in other scales (evaluated areas of life situations of homeless people in shelters).
RO2: Find out if the sex of the respondent (man/woman) affects the closeness of the scale relationships in the questionnaire (evaluated areas of life situations of homeless people in shelters).

RO3: Find out if the length of the stay in the shelter (over/under the median) affects the closeness of the scale relationships in the questionnaire (evaluated areas of life situations of homeless people in shelters).

RO4: Find out if the sex of the respondent (man/woman) affects the percentage of the total level of positive changes (in all scales) from the past to the present.

RO5: Find out if the length of the stay in the shelter (over/under the median) affects the percentage of the total level of positive changes (in all scales) from the past to the present.

RO6: Find out if the sex of the respondent (man/woman) affects the percentage of the total level of negative changes (in all scales) from the past to the present.

R07: Find out if the length of the stay in the shelter (over/under the median) affects the percentage of the total level of negative changes (in all scales) from the past to the present.

The data was analysed using the statistical software R, R Core Team (2018). For the purposes of comparing the ratios between various target groups, we used the score test (Miettinen \& Nurminen, 1985) and its implementation in the R language library (Laud, 2018). For the purposes of correlations estimation, we used the Spearmen correlation coefficient and p-values were calculated by non-parametric methods.

The research implementation was grounded in the Ethical Principles of Psychologists and Code of Conduct (American Psychological Association, 2010) and observed the valid legislation of the Czech Republic.

Possible limitations of the research are reflected in the form of a non-random sampling of the research group; therefore, the achieved results cannot be generalised.

\section{Data analysis and interpretation}

The following part of the paper will present evaluation of research objectives RO1 to RO7:

Evaluation of RO1: The data analysis results reveal that the scale acquisition and retention of housing is mutually (intercon- 
nected) in other scales (evaluated areas of life situations of homeless people in shelters).

Acquisition and retention of housing correlates with the following scales: financial literacy (correlation coefficient: 0.34); meaningful spending of leisure time; self-development (0.38); selfevaluation (0.43); worries about the future (0.30). Acquisition and retention of housing is related by the homeless people in shelters with finances and worries about the future. The above-mentioned implies that self-evaluation and self-development of homeless people is a very important area affecting the acquisition and retention of housing.

Evaluation of RO2: The correlations between scales (evaluated life areas) showed differences based on the respondents' sex. For women, acquisition and retention of housing correlates only with the scale of self-evaluation (0.64). For men, acquisition and retention of housing correlates with scales: financial literacy (0.39); self-development (0.36); self-evaluation (0.34). Acquisition and retention of housing and self-evaluation are thus connected irrespective of the respondent's sex.

Evaluation of RO3: The correlations between scales (evaluated life areas) showed differences based on the respondents' length of stay in the shelter. People whose length of stay in the shelter was over the median showed the correlation of the scale of acquisition and retention of housing with: financial literacy (0.45); meaningful spending of leisure time; self-development (0.45); self-evaluation (0.51). People whose length of stay in the shelter was under the median showed the correlation only with the scales of self-development and life stability (0.43). Connection of financial literacy and acquisition and retention of housing develops in homeless people in shelters over time. Connection of acquisition and retention of housing and self-development seems to be constantly present in the life situation of homeless people living in shelters.

Evaluation of RO4: Positive changes from the past to the present in 3 or fewer areas were experienced by $20.7 \%$ of respondents. Positive changes in 3 or fewer areas from the past to the present was experienced by $26 \%$ of men and $75 \%$ of women. Sex of homeless people living in shelters significantly affects the perception of positive changes. Only a quarter of women perceived their life situation changed at least in more than $\mathbf{4}$ measured areas.

Percentage of positive changes in scales with the highest overall positive percentage changes from the past to the present when dividing respondents according to the sex were:

financial literacy $(67 \%$ of men and $\mathbf{8 2} \%$ of women); acquisition and retention of housing (77\% of men and $\mathbf{8 9 \%}$ women); worries about the future (58\% of men and $\mathbf{8 2} \%$ women);

a life stability (67\% of men and $\mathbf{9 6 \%}$ women). A stay in a shelter is thus perceived by the majority of men and women as a positive change in their housing and financial situation leading to the increase of life stability and a drop in worries about the future.

Evaluation of RO5: Concerning the length of stay in a shelter, positive changes from the past to the present were experienced by $21 \%$ of respondents over the median of the length of stay in the shelter and $24 \%$ of respondents under the median. The length of stay in a shelter does not have a significant impact on the perceived percentage of changes in the areas of the life situation of homeless people.

Evaluation of RO6: At least one negative change from the past to the present was experienced by $47.4 \%$ of the respondents of which $48.4 \%$ men and $45 \%$ women. Therefore, the difference in sex is not significant concerning the experiencing negative changes from the past to the present.

Evaluation of RO7: The difference between the people with the length of stay in shelters over the median and under the median is significant. People living in a shelter over the median of the length of stay in a shelter experienced a negative change in $36 \%$ of cases and people living in a shelter under the median of the length of stay in a shelter experienced a negative change in $56 \%$ of cases. A long-term stay in a shelter is thus a factor with a certain predictive ability to experience negative changes in some of the life areas. Negative changes in scales with the highest overall negative changes from the past to the present when dividing the respondents according to the median of the length of stay in a shelter were: finances $(8.2 \%$ of the respondents over the median and $8.8 \%$ of respondents under the median); meaningful spending of leisure time: work (5.4\% of respondents over the 
median and $5.8 \%$ of respondents under the median); social sources of support $(10.7 \%$ of respondents over the median and $8.9 \%$ of respondents under the median); self-evaluation $(8.8 \%$ of respondents over the median and $7.6 \%$ of respondents under the median).

\section{Discussion, implications, and conclusion}

The result analysis shows that individual life areas of homeless people are mutually interconnected (Groundswell, 2015; Lux \& Mikeszova, 2013). An interesting finding is the fact that acquisition and retention of housing is directly connected with meaningful spending of leisure time similarly as in Gerull \& Merckens (2012) or Groundswell (2015), i.e. with self-development, and self-evaluation of homeless people (similarly, Shier et al., 2010; Weber \& Joubert, 2015). Connection of the acquisition and retention of housing with self-evaluation is not affected by the respondent's sex, however it appeared similarly in Glumbikova et al. (2018a). In context of the above-mentioned, the shelters can be advised to focus more on: a) use of the recovery concept; b) use of the strength-based approach (see f. e. Epstein et al., 2000).

Another interesting factor in relation to shelters operation is that $20.7 \%$ of respondents experienced positive changes in 3 or fewer evaluated areas. There is a significant difference in users living in a shelter under the median (6 months) of length of stay (36\% of respondents) and over the median of the length of stay (56\% of the respondents); the length of stay in a shelter has the potential to increase the percentage of people experiencing a negative change at least in one of the evaluated area; similarly in Lux \& Mikeszova (2013). Most negative changes were experienced in: worries about the future $(15.6 \%)$; meaningful spending of leisure time; self-development (14.4\%); social sources of support (10\%); health $(9.0 \%)$. The above-mentioned implies that shelters should be perceived as only a temporary housing in a crisis situation, not as a tool of social or housing policy leading to full-fledged reintegration (in all observed areas) of permanent housing; similarly in Lux \& Mikeszova (2013).

The research results also show that sex is an important factor to achieve positive changes in individual areas of the lives of homeless people in shelters similarly as in Glumbikova et al. (2018a). Positive changes form the past to the present in 3 or fewer areas were experienced by $75 \%$ women and only $26 \%$ of men. Only a quarter of women perceived that their life situation has changed in at least 4 measured areas. Apart from the above-mentioned, it seems to be necessary to apply a gender-sensitive approach in social work with people living in shelters, which will enable to consider diverse and complex situations of homeless women and men (see f. e. Mayock et al., 2015; Savage, 2016). Recognition of gender in specific life areas of homeless people would help clarify how gender in shelters is reproduced and connected with gender discourses.

This paper has met its objective to evaluate perceived changes in specific life areas from the shelter users' perspective and based on this evaluation to determine the implications for social work in shelters.

\section{Acknowledgements}

The paper was created within the project TJ01000359 financially supported by TA CR.

\section{References:}

1. ANOOSHIAN L J (2005) Violence and Aggression in the Lives of Homeless Children: A Review. Aggression and Violent Behavior, 20 (6): 373-387.

2. AMERICAN PSYCHOLOGICALASSOCIATION (2010).Ethical Principles of Psychologists and Code of Conduct. Washington, DC: American Psychological Association. Retrieved from: http://www.apa.org/ethics/ code/.

3. EPSTEIN M H, RUDOLPH S, EPSTEIN A A (2000) Using Strength-Based Assessment in Transition Planning. Teaching Exceptional Children, 32 (6): 50-54.

4. FEANTSA (2019) Homelessness in Europe, Retrieved from: https://www.feantsa.org/public/user/Resources/magazine/2019/Spring/H omeless_in_Europe_magazine_-_Spring_ 2019.pdf

5. FITZPATRICK-LEWIS D, GANANN R, KRISHNARATNE S, CILISKA D, KOUJOUMDIJAN F, HWANG S W (2011) Effectiveness of Interventions to Improve the Health and Housing Status of Homeless Peo- 
ple: A Rapid Systematic Review. BMC Public Health, 11 (638): 1-14.

6. FOSTER K R, SPENCER D (2011) At Risk of What? Possibilities over probabilities in the study of Young Lives. Journal of Youth Studies, 14 (1): 125-143.

7. GARDNER F (2006) Working with Human Service Organisations: Creating Connections for Practice. Melbourne: Oxford University Press.

8. GERULL S, MERCKENS M (2012) Success Criteria in Helping People with Special Social Difficulties. Folgestudie: Aktenanalyse und Diskussion der Gesamtergebnisse. Uckerland.

9. GLUMBIKOVA K, GOJOVA A, GRUNDELOVA B (2018a) Critical Reflection of the Reintegration Process Through the Lens of Gender Oppression: The Case of Social Work with Mothers in Shelters. European Journal of Social Work, 21: 1369-1457.

10. GLUMBIKOVA K (2017) Reintegration of Single Mothers from Shelters into Permanent Forms of Housing. Ostravská univerzita v Ostravě: Unpublished final work.

11. GROUNDSWELL (2015) The Escape Plan. A Participatory Research Study. Retrieved from: http://www.groundswell.org.uk/The Escape_Plan_Report.pdf

12. HENWOOD B F, DEREJKO K S, COUTURE J, PADGETT D K (2015) Maslow and Mental Health Recovery: A Comparative Study of Homeless Programs for Adults with Serious Mental Illness. Adm Policy Ment Health, 42 (2): 220-228.

13. KUCHAROVA V, JANUROVA K (2016) Size and Structure of Homeless People and Persons Excluded from Housing. Prague: VUPSV.

14. LAPORTE A, LE MENER E, CHAUVIN P (2010) Menthal health and Addictions of People without home. Les Travaux de l'Observatoire. Retrived from: https://www.researchgate.net/publication/255180126_La_sante_m entale_et_les_addictions_des_personnes_san s_logement_personnel_Quelques_eclairages_issus_d'une_enquete_de_prevalence_en IIle-de-France

15. LAUD P (2018) Ratesci: Confidence Intervals for Comparisons of Binomial or Poisson Rates. R package version 0.3-0. Retrived from: https://CRAN.R-project.org/package= ratesci

16. LENS W, PAIXAO M P, HERRERA D (2009) Instrumental Motivation Is Extrinsic Motivation: So What? Psychologica, 50: 2140.

17. LUO Y, MCGRANT C (2006) Oral Health Status of Homeless People in Hong Kong. Special Care in Dentistry, 26 (4): 150-154.

18. LUX M, MIKESZOVA M (2013) Factors of Successful Reintegration of Homeless People and Tools of Housing Policy for Resolving Homelessness in the Czech Republic. Czech Sociological Review, 49: 29-52.

19. MAYOCK P, PARKER S, SHERIDAN S (2015) It's Just Like We're Going Around in Circles and Going Back to Do the Same Thing...', The Dynamics of Women's Unresolved Homelessness. Housing Studies, 30 (6): 877-900.

20. MAYOCK P, CORR M R, O’SULLIVAN E (2011) Homeless Young People, Families and Change: Family Support as a Facilitator to Exiting Homelessness. Child and Familly Social work, 16 (4): 391-401.

21. MIETTINEN O S, NURMINEN M (1985). Comparative analysis of two rates. Statistics in Medicine, 4: 213-226.

22. MOLSA (2015) Social Housing Concept of Czech Republic 2015-2025. Retrived from: https://www.mpsv.cz/files/clanky/27267/Koncepce_socialniho_bydleni_CR_2015-2025.pdf

23. MOLSA (2013) Concept of Preventing and Tackling Homelessness Issues in the Czech Republic until 2020. Retrieved from: https:// www.mpsv.cz/files/clanky/19647/brozura_E N_A5_vnitrek_tisk.pdf

24. NEALE J, STEVENSON C (2015) Social and Recovery Capital among Homeless Hostel Residents Who Use Drugs and Alcohol. International Journal of Drug Policy, 26: 475-483.

25. PATTERSON A, TWEED R (2009) Escaping Homelessness: Anticipated and Perceived Facilitators. Journal of Community Psychology, 37 (7): 846-858.

26. R CORE TEAM (2018) R: A Language and Environment for Statistical Computing. R Foundation for Statistical Computing, Vienna, Austria. Retrieved from: https://www. R-project.org/. 
27. SAVAGE M (2016) Gendering Women's Homelessness. Irish Journal of Applied Social Studies, 16 (2): 4.

28. SHIER M L, JONES M E, GRAHAM J R (2010) Perspectives of Employed People Experiencing Homelessness of Self and Being Homeless: Challenging Socially Constructed Perceptions and Stereotypes. Journal of Sociology \& Social Welfare, 37 (4): 13-37.

29. SHOBE M, PAGE-ADAMS D (2001) Assets, Future Orientation, and Well-Being: Exploring and Extending Sherraden 's Framework. The Journal of Sociology \& Social Welfare, 28 (3): 109-127.

30. TOWERS G (2000) Shelter is Not Enough: Transforming Multi-storey Housing. London: Bristol University Press.

31. WEBER M, JOUBERT L (2015) Social Work and Recovery. British Journal of Social Work, 45 (1): 1-8. 